
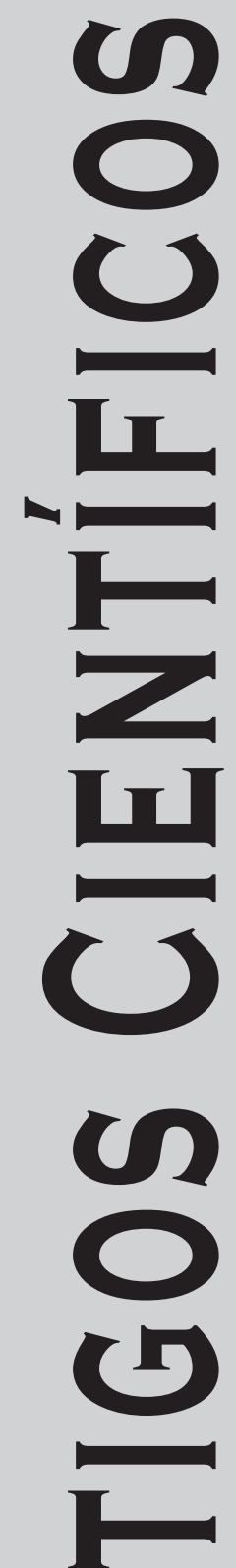
ac

Revista Música Hodie, Goiânia - V.14, 238p., n.1, 2014 


\title{
A Anadiplose Aplicada à Estrutura Musical
}

\author{
Jorge Antunes (UnB, Brasília, DF) \\ antunes@unb.br
}

\begin{abstract}
Resumo: Este trabalho apresenta um relato sobre a composição de uma obra eletroacústica, em que o autor utilizou uma figura de sintaxe, muito usada na poesia, para a construção da estrutura musical. A figura adotada foi a anadiplose. A música figural tem utilizado deste recurso, com a intenção de trazer à música a capacidade de persuasão e sedução que poetas e oradores costumam usar, por meio da arte da retórica. O trabalho aqui analisado, entretanto, se reveste de caráter especial, porque a obra musical, usando a anadiplose em sua estrutura, fez uso de um texto poético falado em que se destaca a figura da anadiplose. A experiência demonstra a força expressiva da música, reforçada pela força expressiva do próprio poema utilizado. Significados e significantes se entrelaçam. Objetos sonoros e objetos musicais se igualam. Vocabulário e linguagem se amalgamam, dando lugar à eloquência na música eletroacústica. Concluiu-se da pertinência do processo composicional, através da apropriação formal de uma das mais importantes figuras de linguagem próprias da Retórica: a anadiplose.
\end{abstract}

Palavras-chave: Anadiplose; Tirzo de Molina; Retórica; Persuasão; Semântica musical; Música eletroacústica; Música figural.

The anadiplose applied to musical structure

Abstract: This text presents an account about the composition of an electroacoustic work, in which the author used a figure of syntax, much used in poetry, for the construction of a musical structure. The figure was the anadiplose. The figural music has used this resource with the intention of bringing music to the ability of persuasion and seduction that poets and orators often use through the art of rhetoric. The work discussed here, however, is of special character because the musical composition, using anadiplose in its structure, made use of a poetic spoken text which highlights the figure of anadiplose. The experiment demonstrates the expressive power of music, enhanced by the expressive power of the poem itself used. The signifiers and meaning intertwine. Sound objects and musical objects are equal. Vocabulary and language amalgamate, giving rise to eloquence in electroacoustic music. It was concluded on the relevance of the compositional process, through formal ownership of one of the most important figures of speech used in rhetoric: a anadiplose.

Keywords: Anadiplose; Tirzo Molina; Rhetoric, Persuasion; Musical semantics; Electroacoustic music; Figural music.

\section{A retórica de Aristóteles}

Aristóteles distinguiu três grandes gêneros na Retórica (Aristóteles, 1997): o "epidítico”, com um estilo divertido e agradável, em que o público comanda o elogio ou a censura; o "judiciário", em que se determina se uma ação é justa ou não; e o “deliberativo”, em que se deve decidir acerca de uma ação, em função de uma utilidade ou de uma nocividade. Esses três gêneros têm um componente de "ethos", um de "pathos" e um outro de "logos". Enfim, a audiência julga se o discurso é belo (epidítico), justo (judiciário) ou útil (deliberativo) (Gardes-Tamine, 1996).

O componente "ethos" está presente no comunicador, que no âmbito da fala é o orador e no domínio da música é o dipolo compositor-intérprete. O componente "pathos”, cuja origem etimológica se refere às reações da alma, se localiza no domínio das paixões. O componente "logos" (jogo) está presente também nos três gêneros: nas retóricas epidítica, judiciária e deliberativa sempre se joga com o que "seria possível”, com o que "é possível” e com o que "será possível” (Cooper, 1967). 


\section{Epidítico}

Nas relações interpessoais é comum ouvirmos: “- Como vai?”

O outro responde: “- Tudo bem. Como vai?"

$\mathrm{Na}$ verdade um não está realmente interessado em saber como vai o outro. Esses cumprimentos muitas vezes antecedem diálogo ácido, que tratará de assuntos delicados. As saudações iniciais são sempre importante, para estabelecer uma polidez que abranda ou minimiza eventuais agressividades em potencial.

De acordo com Esther Godoy esses e outros aspectos da comunicação humana têm por objetivo diminuir a "distância" entre os indivíduos. Dessa forma logo de início se verifica "uma negociação para que se concretize a diminuição dessa distância. O epidítico, que visa anular a distância, preenche perfeitamente essa função” (Godoy, 1978).

\section{Persuasão e sedução}

Em trabalhos anteriores descrevi a identificação de várias figuras de linguagem na música eletroacústica. Aqui pretendo ressaltar alguns tipos de fenômeno provocados, durante a comunicação musical, pelas sintaxes que usam semantemas (Antunes, 2001a, 2001b): o “convencimento", a “comoção” e a “persuasão” (Antunes, 2004).

Introduzo, para tanto, outra palavra que bem define a intenção do compositor no processo de "conquistar" o público: a "sedução".

O conceito de "sedução" vem sendo aplicado apenas na publicidade, na propaganda, nas relações amorosas e na política. Mas não é apenas nesses quatro processos de comunicação que a "sedução" se faz presente. Também na música podemos falar de uma "retórica da sedução". No fenômeno da comunicação musical também encontramos o discurso indireto, figurado, que não diz de modo literal aquilo que motiva ou inspira o comunicador ou o autor, mas que, embora não dito, é involucrado em sintaxes pelo compositor, com táticas e estratégias revelando a intenção de que algo velado seja percebido e assimilado pelo público.

O compositor de música eletroacústica além de pretender "convencer" e "comover", não mais apenas praticando o puro deleite sonoro, trata muitas vezes de tentar "seduzir" o ouvinte. A pesquisa que venho desenvolvendo volta-se à busca e identificação de elementos de linguagem que denotam evidências de uma "eloquência eletroacústica".

\section{Elocuções figuradas e LIEM}

No Livro IX, Quintiliano estuda a "Elocução Figurada”, detendo-se nas "Figuras das Palavras". É no Artigo I do capítulo III que encontramos as principais figuras: anáfora, epístrofe, poliptóton, anadiplose, epizeuxe, reduplicação, diácope, simploce, epanalepse, epânodo, sinonímia, exergásia, polissíndeto e gradação (Quintiliano, 1944).

Uma das figuras de linguagem mais propícias à construção musical é a anadiplose.

Em 2008, como resultado do Premio Estancias que ganhei do Ministério da Cultura da Espanha, desenvolvi um projeto de composição no Estúdio de Música Eletroacústica do LIEM (Laboratório de Informática y Electroacústica Musical) de Madrid. No LIEM compus quatro obras, todas baseadas em poemas usando figuras de sintaxe.

Uma dessas obras, intitulada Anadiplosia para Tirzo, com pouco mais de 7 minutos de duração, tem sido reconhecida como peça de grande expressividade e capacidade de comunicação. 


\section{Anadiplose}

Anadiplose é a figura retórica que consiste em repetir no princípio de um verso, ou de uma frase, uma palavra que estava no final do verso anterior ou da frase anterior.

Eis um exemplo de anadiplose, no poema do espanhol José de Espronceda intitulado A la muerte de Torridos y sus compañeros:

"Españoles, llorad; mas vuestro llanto

lágrimas de dolor y sangre sean,

sangre que ahogue a siervos y opresores"

(Espronceda, A la muerte de Torridos y sus compañeros)

Em Shakespeare encontramos interessantes exemplos de anadiplose. Eis um deles:

"The love of wicked men converts to fear,

That fear to hate, and hate turns one or both

To worthy danger and deserved death."

(Shakespeare, Richard II 5.1.66-68)

Encontramos a anadiplose em alguns poemas de autores brasileiros:

"Contou muitas histórias.

Histórias de lembranças"

(Álvaro Moreira, Havia uma Oliveira no Jardim, p. 104)

"E a fonte, rápida e fria,

Com um sussurro zombador,

Por sobre a areia corria,

Corria levando a flor."

(Vicente de Carvalho, Poemas e Canções, p. 263)

"O dia surge todo de bruma,

todo de bruma, todo de neve."

(Alphonsus de Guimaraens, Obras Completas, p. 117)

Na música eletroacústica, em que a eloquência na transmissão de uma idéia musical pudesse se manifestar, o uso da anadiplose deverá se inserir na construção em que um mesmo objeto sonoro, ou um mesmo semantema, se encontre no final de uma frase e, com repetição, no início da frase seguinte.

Foi o critério que usei na construção da obra Anadiplosia para Tirzo.

\section{Tirzo de Molina}

Tirso de Molina foi um religioso espanhol que viveu de 1579 a 1648. Seu nome verdadeiro era Fray Gabriel Téllez. Foi escritor dramático e poeta, deixando-nos importantes textos teatrais. Tendo tratado, em seus escritos, de temas profanos com ideias arrojadas, foi um criador bastante polêmico. Escreveu 400 comédias de todos os tipos, tornando-se famoso pela criação do tipo Don Juan. Suas obras mais importantes são El burlador de Sevilla, Don Gil de las calzas verdes, El vergonzoso em palacio e El condenado por desconfiado.

É da autoria de Tirzo de Molina, uma das mais poéticas e belas construções com anadilose: 
“¿Ves essas yedras y parras de esos alamas enredos?

Pues celosas de sus hojas, tienen ya sus troncos secos.

Celos que del prado tiene, hacen que aquel arroyuele hechos labios sus cristales, se coma aquel lirio a besos.

No hay criatura sin amor, amor sin cellos perfecto, ni celos libres de engaños.

Ni engaños sin fundamento.”

(Tirzo de Molina, La Gallega Mari-Hernández)

O poema é um trecho da peça teatral La Gallega Mari-Hernández. Trata-se da fala de um dos personagens, ao se referir à sensualidade, ao amor e ao ciúme produzidos pela atração dos corpos. O material sonoro que utilizei na composição eletroacústica foi basicamente a gravação dessas três quadras, na voz da pianista Ana Vega-Toscano que é locutora profissional da Radio Nacional da Espanha.

A composição musical teve sua estrutura previamente estabelecida, de modo a se constituir em um discurso musical com a forma da anadiplose. Ou seja, obejetos sonoros usados no final de uma frase se repetem no início da frase seguinte.

A Figura 1 ilustra a estrutura da primeira seção da obra. Ela é constituída de 4 frases, em configuração simétrica. A segunda frase inicía com o elemento B processado: a primeira frase termina com o elemnto B. O elemento A aparece no final da segunda frase e ele mesmo, processado, está no início da terceira frase. Esta termina com o elemento C, que é repetido, processado e multiplicado em estereofonia espacial, no início da quarta frase. O período de quatro frase termina com o processamento do elento D, que foi usado no início da primeira frase e da obra.

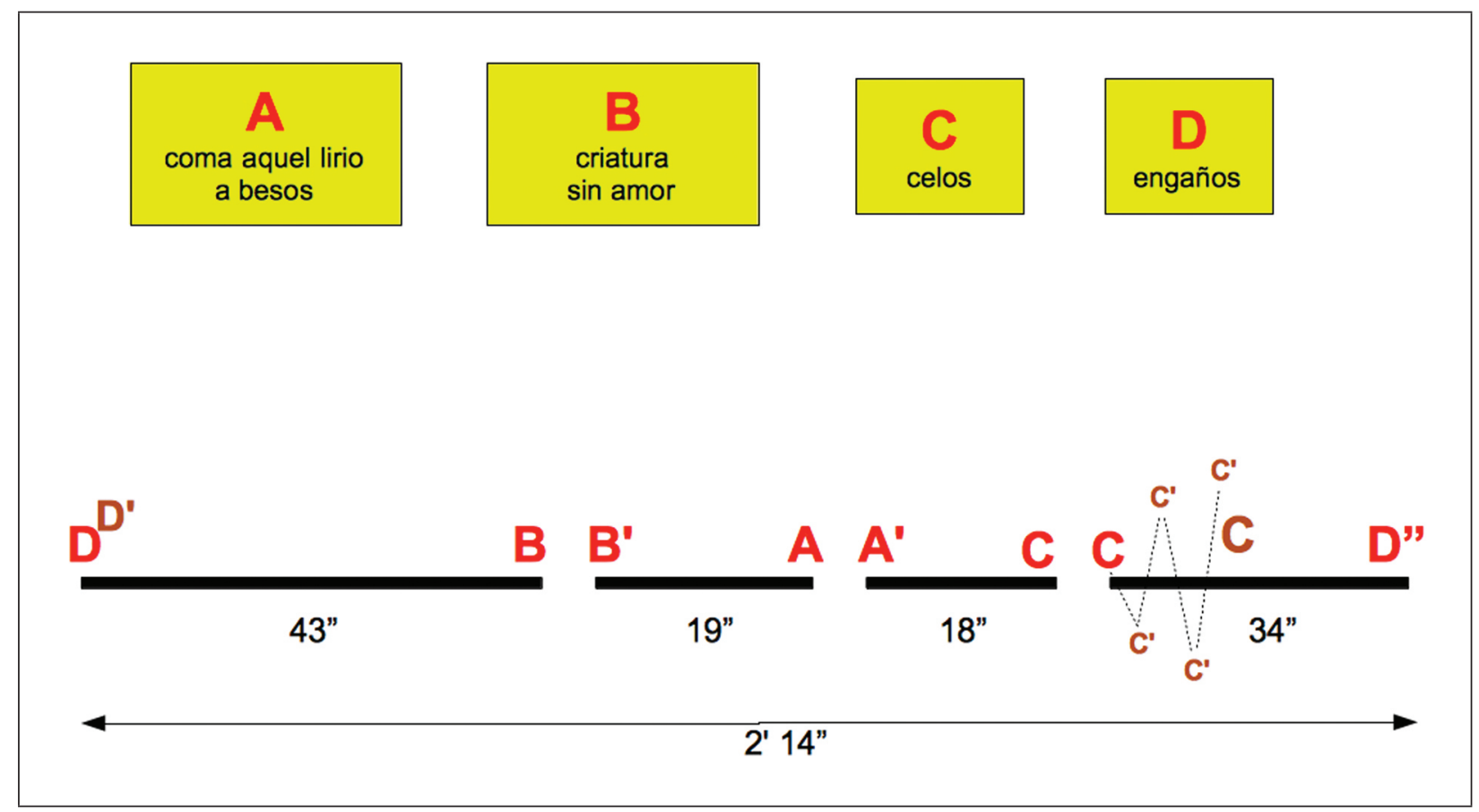

Figura 1 
A Figura 2 mostra a estrutura total da obra, com suas três seções. A segunda seção é uma espécie de grande divertimento, com o mesmo espírito dos desenvolvimentos da sonata: elementos básicos são desenvolvidos e multiplicados com diversos tipos de processamento eletroacústico, com repetições espaciais, dando lugar a um final em que é explorada a palavra "amor".

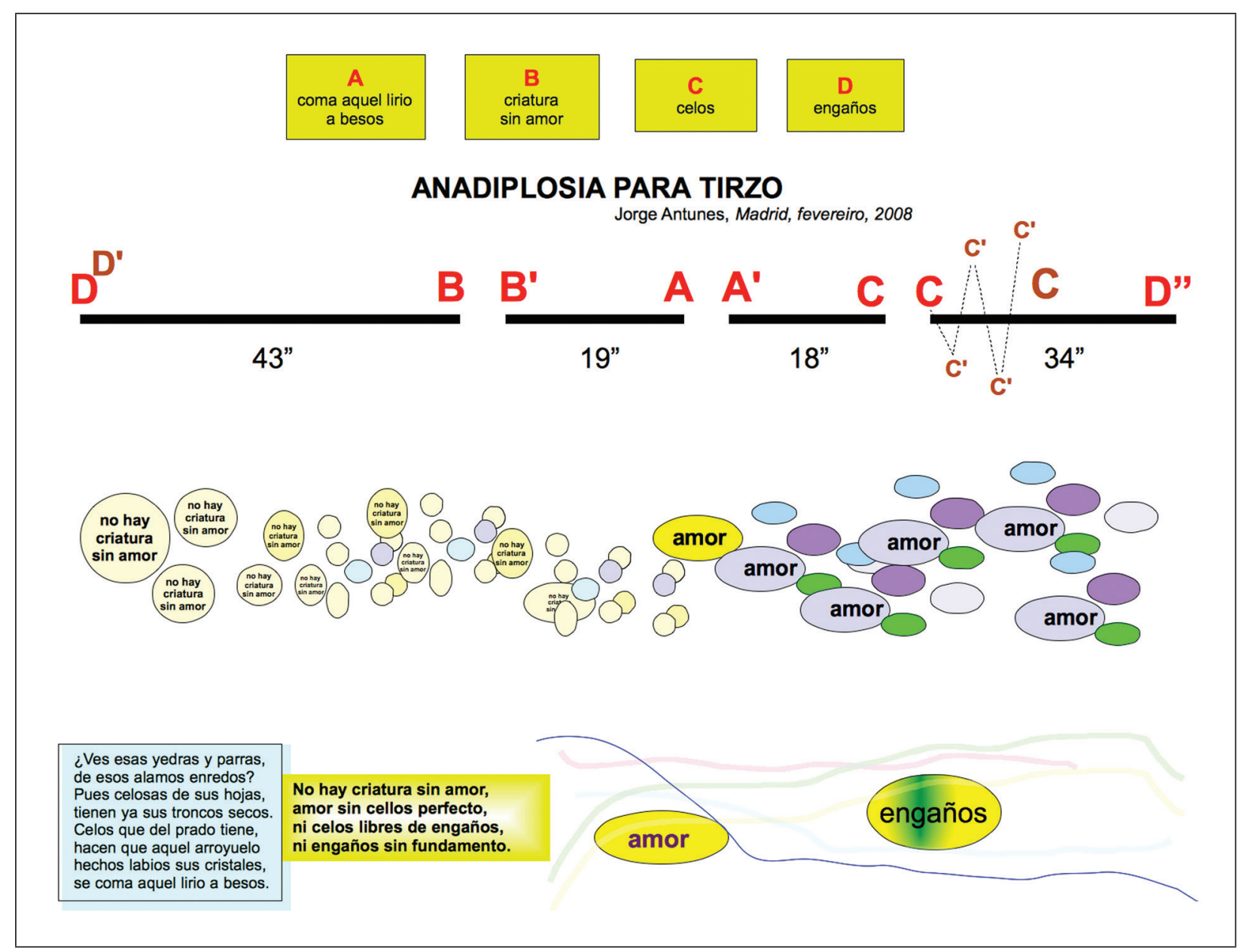

Figura 2

A terceira seção da obra desafia os cânones da música eletroacústica tradicional, porque se inicia com uma linguagem de poesia sonora. O texto é apresentado na íntegra, com uma voz sensual, em interpretação de Ana-Vega Toscano, em espanhol arcaico autêntico.

Na parte final da obra, segunda parte da terceira seção, um desenvolvimento e uma coda privilegiam as duas palavras chave do poema: "amor" e "engaños".

Todas as transformações e processamentos foram realizados com modos de extensão do programa GRM-Tools: FreqShift, FreqWarp, PitcAccum, Flanger, Doppler e Comb Filter.

\section{Conclusões}

Na experiência evitou-se a ocorrência da redundância que a expressão lierária e a expressão musical poderiam apresentar. O recurso da anadiplose na construção musical não foi usado com as palavras e os versos de Molina em que o poeta usa a anadiplose. O uso da figura de linguagem anadiplose, como modelo de base para uma estrutura musical, se revela muito eficaz em uma obra eletroacústica, ao facilitar a comunicação com o público. 
Isso foi demonstrado nos concertos em que apresentei a obra, em Madri e em Brasília, e nos debates que se seguiram com o público.

Os indícios de uma possível eloquência na música eletroacústica, que demonstra a intenção do compositor em seduzir a escuta por meio de gestos poéticos, acende luzes que podem iluminar as estruturas da nova música como algo mais do que uma simples meta-linguagem.

\section{Referências}

ANTUNES, Jorge (1998). Volatas e Cascatas: primeiras identificações de semantemas musicais na música eletroacústica, com base em significações do tipo "emoção forte". In: Anais do XI Encontro Nacional da Anppom. XI Encontro Nacional da Anppom, Campinas, 1998, 156-161.

. (1999). Baques e Quicadas: novas identificações de semantemas musicais na música eletroacústica, com base em significações do tipo "emoção forte". In: Anais do XII Encontro Nacional da Anppom. XII Encontro Nacional da Anppom, Salvador, 1999, CD-Rom.

. (2001a). O Semantema. In: Opus no 7. In: Revista eletrônica da Anppom, 2001. Disponível em: <http://www.musica.ufmg.br/anppom/opus/opus7/antmain.htm>. Acessado em: 28/05/2006.

. (2001b). Clamores e Argumentos: identificação de semantemas musicais na música eletroacústica, com base em significações do tipo "persuasão". In: Anais do XI Encontro Nacional da Anppom. XI Encontro Nacional da ANPPOM, Belo Horizonte, 2001, 253-260.

. (2004). Anáfora, Epístrofe e Poliptóton: identificação de figuras de linguagem na música eletroacústica, no âmbito da retórica e da eloquência, com base em significações do tipo "persuasão" In: Anais do XIV Encontro Nacional da Anppom. XIV Encontro Nacional da Anppom, Porto Alegre, 2004.

ARISTÓTELES (1997). Poética. São Paulo: Editora Cultrix. Tradução direta do grego e do latim de Jaime Bruna: A Poética Clássica.

COOPER, Lane (1967). Aristotle on the Art of Poetry, an amplified version with supplementary illustrations. Ithaca: Cornell University Press.

GARDES-TAMINE, J. (1996). La réthorique. Paris: Armand Colin.

GODOY, Esther (1978). Questions and Politeness, Cambridge: Cambridge Press.

QUINTILIANO, M. Fábio (1944). Instituições Oratórias. São Paulo: Edições Cultura, 1944. Tradução de Jerônimo Soares Barbosa. 2 Tomos.

\footnotetext{
Jorge Antunes - Formou-se em violino, composição e regência. Realizou estudos pós-graduados em composição no Instituto Torcuato Di Tella de Buenos Aires. Estudou no Instituto de Sonologia da Universidade de Utrecht, com uma bolsa do governo holandês, e no Groupe de Recherches Musicales de l'ORTF, onde atuou como compositor-estagiário sob a orientação de Pierre Schaeffer. Fez o Doutorado em Estética Musical na Sorbonne, Universidade de Paris VIII, tendo Daniel Charles como orientador. Ingressou em 1973 no corpo docente da Universidade de Brasília. Foi Professor Titular de Composição Musical na UnB até 2011, quando se aposentou. Continua vinculado àquela Universidade, como Pesquisador Sênior. Obteve vários prêmios nacionais e internacionais. Tem vários CDs, DVDs e livros publica- dos. É membro da Academia Brasileira de Música e Presidente da Sociedade Brasileira de Música Eletroacústica. Suas obras são publicadas por importantes editoras internacionais: Salabert, Breitpkof\&Hartell, Gerig, Ricordi, Sistrum, Billaudot e Suvini Zerboni.
} 